\title{
The Interaction of Single Nucleotide Polymorphisms on Fibroblast Growth Factor 19 Superfamily Genes Is Associated With Alcohol Dependence-Related Aggression
}

\author{
Jinzhong $\mathrm{Xu}^{1+}$, Fenzan $\mathrm{Wu}^{2 \dagger}$, Fan Wang ${ }^{3,4+}$, Fan Yang ${ }^{5}$, Meng Liu ${ }^{5}$, Mengbei Lou ${ }^{5}$,

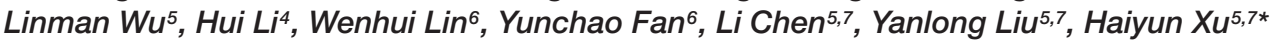 \\ and Jue $\mathrm{He}^{7,8,9,10 *}$
}

\begin{abstract}
' Department of Clinical Pharmacy, Affiliated Wenling Hospital, Wenzhou Medical University, Wenling, China, ${ }^{2}$ Laboratory of Translational Medicine, Affiliated Cixi Hospital, Wenzhou Medical University, Ningbo, China, ${ }^{3}$ Psychiatry Research Center, Beijing Hui-Long-Guan Hospital, Peking University, Beijing, China, ${ }^{4}$ Xinjiang Key Laboratory of Neurological Disorder Research, The Second Affiliated Hospital of Xinjiang Medical University, Ürümqi, China, ${ }^{5}$ School of Mental Health, Wenzhou Medical University, Wenzhou, China, ${ }^{6}$ Department of Cardiovascular Medicine, Affiliated Wenling Hospital, Wenzhou Medical University, Wenling, China, ${ }^{7}$ The Affiliated Kangning Hospital, Wenzhou Medical University, Wenzhou, China, ${ }^{8}$ Xiamen Xian Yue Hospital, Xiamen, China, ${ }^{9}$ First Affiliated Hospital, Institute of Neurological Disease, Henan University, Kaifeng, China, ${ }^{10}$ Institute of Aging, Key Laboratory of Alzheimer's Disease of Zhejiang Province, Wenzhou Medical University, Wenzhou, China
\end{abstract}

OPEN ACCESS

Edited by: Yidong Wang,

Xi'an Jiaotong University, China

Reviewed by:

Xingguang Luo,

Yale University, United States

Lijing Wang,

University of Michigan, United States

*Correspondence:

Jue He

hejue2002@hotmail.com

Haiyun Xu

hyxu@stu.edu.cn

${ }^{\dagger}$ These authors have contributed equally to this work

Specialty section: This article was submitted to Stem Cell Research,

a section of the journal

Frontiers in Genetics

Received: 15 April 2021

Accepted: 22 June 2021

Published: 18 August 2021

Citation:

$X u$ J, Wu F, Wang $F$, Yang $F$. LiU M, Lou M, Wu L, Li H, Lin W,

Fan Y, Chen L, Liu Y, Xu H and He J (2021) The Interaction of Single

Nucleotide Polymorphisms on

Fibroblast Growth Factor 19 Superfamily Genes Is Associated With

Alcohol Dependence-Related Aggression. Front. Genet. 12:695835.

doi: 10.3389/fgene.2021.695835

Alcohol dependence (AD) is characterized by compulsive alcohol consumption, which involves behavioral impairments such as aggression. Members of fibroblast growth factor (FGF) 19 superfamily, including FGF19, FGF21, and FGF23, are major endocrine mediators that play an important role in alcohol metabolism and alcohol related disorders. The objective of the present study is to explore the possible associations among the interaction of single nucleotide polymorphisms (SNPs) of the FGF 19 superfamily, $A D$ occurrence, and aggression in patients with $A D$. A total of 956 subjects were enrolled in this study, including 482 AD patients and 474 healthy controls (HCs). Michigan alcoholism screening test (MAST) was used to measure the level of $A D$, a Chinese version of the Buss-Perry Aggression Questionnaire was used to evaluate the aggressive behavior of subjects, and MassARRAY@ system was used to genotype rs948992 of FGF19, rs11665841 and rs11665896 of FGF21, rs7955866 and rs11063118 of FGF23. The results showed that AD patients presented a significantly higher level of aggression compared to HCs, and MAST scores were significantly positively associated Buss-Perry aggression scores $(r=0.402, p<0.001)$ in AD patients. The interaction of FGF19 rs948992 TC $\times$ FGF21 rs11665896 GG presented the high-risk genotype combination predicting the high level of $A D$. In addition, the interaction of FGF19 rs948992 TC $\times$ FGF21 rs11665896 TG $\times$ FGF23 rs11063118 TT presented the high-risk genotype combination predicting the high level of aggression in $A D$ patients. Our results added evidence linking the combination of rs948992 TC $\times$ rs11665896 TG $\times$ rs11063118 $T$ to aggressive behavior in AD patients and pointed out the potential usefulness of the SNPs of FGF19 superfamily as a predictor for the aggression in AD patients.

Keywords: FGF21, FGF19, FGF23, alcohol dependence, aggression, single nucleotide polymorphism 


\section{INTRODUCTION}

Alcohol dependence $(\mathrm{AD})$ is a common psychiatric disorder and is characterized by loss of control over alcohol drinking, which is associated with impaired decision-making, seeking alcohol regardless of health status and behavioral impairments such as aggression and impulsivity, even suicide attempts (Tobore, 2019; Witkiewitz et al., 2019). Pieces of evidence suggested that AD was a multifactorial and genetic disease, and the pathogenesis of $\mathrm{AD}$ included neurobiological, genetic and epigenetic, psychological, social, and environmental factors (Kiive et al., 2017; Newman et al., 2018; Malamut et al., 2021). Some patients with AD recover after lifestyle modifications in the absence of medical treatment, while many of them relapse and display damaged brain structure and function (Grant et al., 2015; Abrahao et al., 2017; Erickson et al., 2019). AD is usually reported to combine with behavioral impairments or mental disorders such as aggression, suicide, major depression, anxiety, insomnia, and drug addiction (Dick and Agrawal, 2008; Schuckit, 2009).

As a harmful behavior induced by $\mathrm{AD}$, aggression is an important alcohol-related phenotype and could endanger other individuals and society in general through violence and even crime (Heinz et al., 2011; Chester et al., 2020). Increasing evidence suggested that neurobiological, genetic and epigenetic mechanisms such as the involvement of dopamine, serotonin, gamma-aminobutyric acid (GABA), and neuroendocrine systems may be related to $\mathrm{AD}$ and $\mathrm{AD}$-related aggression (Heinz et al., 2011; Nedic Erjavec et al., 2014; Gan et al., 2015; Plemenitas et al., 2015; Waltes et al., 2016). The environmental factors and specific genes may be the important causes for AD and alcoholuse disorders including aggression (Schuckit, 2009; Plemenitas et al., 2015). The interaction among the single nucleotide polymorphisms (SNPs) of genes of oxytocin and its receptor was reported to be related to alcohol disorder and aggressive behavior (Yang et al., 2017). The GABA type A receptor subunit alpha (GABRA) 2 rs279826/rs279858 A-allele interacts with stress, contributing to the development of alcohol use and aggressive behavior (Kiive et al., 2017).

Fibroblast growth factor (FGF) 19, FGF21, and FGF23 belong to FGF19 superfamily. The members of this subfamily are characterized by their reduced binding affinity for heparin that enables them to be transported in the circulation and function in an endocrine manner (Kharitonenkov and DiMarchi, 2017). The proteins of FGF19 subfamily influence the enterohepatic circulation of bile, participate in glucose and lipid metabolism regulation, and maintenance of phosphorus and vitamin D3 homeostasis (Dolegowska et al., 2019). Recent studies suggest that FGF19, FGF21, and FGF23 are associated with alcohol and alcohol-related disorders (Schumann et al., 2016; QuinteroPlatt et al., 2017; Brandl et al., 2018; Gonzalez-Reimers et al., 2018; Epperlein et al., 2021). Serum FGF19 level and FGF19 mRNA expression both increase strongly in patients with alcohol use disorder (Brandl et al., 2018). The circulating FGF 21 level also increased significantly after binge alcohol consumption (Desai et al., 2017). Studies suggested heavy alcohol intake could induce FGF 21 high expression, however, overexpressing FGF 21 may decrease alcohol preference by regulating the drinking behavior in part through SIM1positive neurons of the hypothalamus (Desai et al., 2017; Soberg et al., 2018; Song et al., 2018). In alcoholic patients, the levels of FGF 23 also increased significantly (QuinteroPlatt et al., 2017). The evidence about FGF19 superfamily members associated with alcohol consumption is relatively abundant, but the reports about FGF19 superfamily members' polymorphisms with $\mathrm{AD}$ are still rare. A study found that the A allele of rs838133 on the FGF21 gene is significantly associated with increased alcohol intake (Soberg et al., 2017). Another study demonstrated that the FGF19/21- $\beta$-Klotho signaling pathway is associated with alcohol consumption and the substream essential receptor protein $\beta$-Klotho gene SNP rs11940694 is significantly related to alcohol intake (Schumann et al., 2016).

As an important member of the FGF19 superfamily, FGF21 has an extensive biologic effect on mediating the central nervous system. FGF21 might be involved in mood disorders through stimulating dopamine signaling in the prefrontal cortex (Chiavaroli et al., 2017). A recent study has indicated that FGF21 was significantly associated with alcohol craving (Epperlein et al., 2021), which is associated with aggression in patients with alcohol use disorder (Roozen et al., 2013; Park et al., 2019). FGF21 genetic or near the FGF21 locus variants are associated with carbohydrate preference and consumption of addictive substances (Heianza et al., 2016; Frayling et al., 2018). Furthermore, physiological effects of FGF21 were tightly correlated with the dopamine and serotonin system (Han et al., 2016; Recinella et al., 2017; Gibson, 2018), which both play an important role in mediating aggressive behavior (Brodie et al., 2016). All the above studies indicate a potential association between FGF19 superfamily and aggressive behavior.

The rs948992 of FGF19 SNP and rs11665841 and rs11665896 of FGF21 SNPs are located on 3' untranslated region (3'UTR; Zhang et al., 2012), ${ }^{1}$ where miRNAs could bind and further impact target gene protein translation (Chen and Rajewsky, 2006; Landi et al., 2008). The genetic variants of miRNA target sites may induce phenotypic changes and increase the risk of developing diseases (Sethupathy and Collins, 2008; Zhang et al., 2012). The sequence variation C716T (rs7955866) is located in exon 3 of FGF23 gene, which could affect the FGF23 activity by the missense variation designated $\mathrm{T} 239 \mathrm{M}$ and the exchange of T239M (Nguyen et al., 2010). In addition, rs11063118 of FGF23 was selected based on the tagging SNP approach, optimal sets of SNPs were derived from genetic databases in order to tag haplotypes across genes (Rothe et al., 2017). Thus, in order to explore the possible associations of FGFs 19, 21, and 23 polymorphisms with $\mathrm{AD}$ and $\mathrm{AD}$-related aggression, rs948992 of FGF19, rs11665841, and rs11665896 of FGF21, and rs7955866 and rs11063118 of FGF23 were chosen to evaluate genotypes by using MassARRAY@ system, Michigan alcoholism screening test (MAST) was used to measure the level of $\mathrm{AD}$, and a Chinese version of the Buss-Perry Aggression Questionnaire was used to evaluate the aggressive behavior of subjects in the present study.

\footnotetext{
${ }^{1}$ https://www.ncbi.nlm.nih.gov/snp/rs948992
} 


\section{MATERIALS AND METHODS}

\section{Subjects}

A total of 956 unrelated Han population males aged above 18 years in northern China were recruited in this crosssection study, including 482 patients in $\mathrm{AD}$-group and 474 healthy control subjects in HC-group. Because there were too few female patients with $\mathrm{AD}$ in this study, they were excluded. All alcoholism patients were diagnosed according to the Diagnostic and Statistical Manual of the American Psychiatric Association, fourth edition (DSM-IV). Participants with the following conditions were excluded: had a family history of psychosis and neurological diseases, severe systemic diseases, central nervous system diseases, cancer, and cognitive impairment. According to self-reporting and confirmation by the next of kin and family members, subjects with a history of drug abuse or dependence were also excluded, except for alcohol and nicotine abuse. The clinical characteristics data were collected after enrollment including age, years of education, marital status, and living conditions.

\section{The Assessment of Aggression Associated With Alcohol Dependence}

The Chinese version (Yang et al., 2017) revised from Buss-Perry Aggression Questionnaire (Buss and Perry, 1992) was used to measure five aspects of human aggression. The original 29-item scale with 4 subscales became a 30 -item scale with 5 subscales: physical aggression (7 items), verbal aggression (5 items), anger (6 items), hostility (7 items), and aggression toward self (5 items). All items are 5-point Likert scales (none, seldom, sometimes, often, and always) scored $0-4$, so the total score ranges from 0 to 120 with higher scores representing greater aggression. In addition, the MAST was performed to evaluate the influence of alcohol on individuals with AD (Selzer, 1971). The MAST is a 25-item, self-report questionnaire on which respondents rate the severity of a range of $\mathrm{AD}$ using a 4-point scale ranging from 1 (not at all) to 4 (extremely). The scale has high internalconsistency reliability, with alpha values of 0.90 (Skinner, 1982). Higher scores indicate greater AD. This study was approved by the Peking University Institutional Review Board. For each participant, written informed consent was obtained directly from the subjects or their responsible guardians. All procedures performed in this study involving human participants were following the 1964 Helsinki declaration and its later amendments or comparable ethical standards.

\section{Selection and Genotyping of Single Nucleotide Polymorphism}

Genomic DNA was extracted from $5 \mathrm{ml}$ peripheral blood using the salting-out method from all the subjects (Tian et al., 2008). Buffy coats of nucleated cells obtained from anticoagulated blood (ACD or EDTA) were resuspended in $15 \mathrm{ml}$ polypropylene centrifugation tubes with $3 \mathrm{ml}$ of nuclei lysis buffer $(10 \mathrm{mM}$ Tris- $\mathrm{HCl}, 400 \mathrm{mM} \mathrm{NaCl}$, and $2 \mathrm{mM} \mathrm{Na}_{2}$ EDTA, $\mathrm{pH}$ 8.2). The cell lysates were digested overnight at $37^{\circ} \mathrm{C}$ with $0.2 \mathrm{ml}$ of $10 \%$ SDS and $0.5 \mathrm{ml}$ of a protease $\mathrm{K}$ solution ( $1 \mathrm{mg}$ protease $\mathrm{K}$ in $1 \%$ SDS and $2 \mathrm{mM} \mathrm{Na}_{2}$ EDTA). After digestion was complete,
$1 \mathrm{ml}$ of saturated $\mathrm{NaCl}$ (approximately 6M) was added to each tube and shaken vigorously for $15 \mathrm{~s}$, followed by centrifugation at 2,500 rpm for $15 \mathrm{~min}$. The precipitated protein pellet was left at the bottom of the tube and the supernatant containing the DNA was transferred to another $15 \mathrm{ml}$ polypropylene tube. Exactly 2 volumes of room temperature absolute ethanol was added and the tubes inverted several times until the DNA precipitated. The precipitated DNA strands were removed with a plastic spatula or pipette and transferred to a $1.5 \mathrm{ml}$ microcentrifuge tube containing 100-200 $\mu \mathrm{l}$ TE buffer $(10 \mathrm{mM}$ Tris- $\mathrm{HCl}, 0.2 \mathrm{mM}$ $\mathrm{Na}_{2}$ EDTA, pH 7.5). The DNA was allowed to dissolve $2 \mathrm{~h}$ at $37^{\circ} \mathrm{C}$ before quantitating (Miller et al., 1988). Three SNPs of the gene including rs948992, rs11665841, rs11665896, rs7955866, and rs11063118 were genotyped using MALDI-TOF based scalable MassARRAY@ System (Agena Bioscience, Inc., San Diego, CA, United States). The protocol was performed according to the manufacturer's instructions. The primers are shown in Table 1. All the laboratory procedures were carried out in a blind manner to case/control status. The conditions of PCR were as follows: $94^{\circ} \mathrm{C}$ for $30 \mathrm{~s}\left[40\right.$ cycles $\times\left(94^{\circ} \mathrm{C}\right.$ for $\left.5 \mathrm{~s}\right), 5$ cycles $\times\left(52^{\circ} \mathrm{C}\right.$ for $5 \mathrm{~s} 80^{\circ} \mathrm{C}$ for $5 \mathrm{~s}$, and $72^{\circ} \mathrm{C}$ for $\left.\left.3 \mathrm{~min}\right)\right]$. Ten percent of the DNA samples were duplicated randomly and tested, and no-fault genotyping was found.

\section{Statistical Analysis}

Continuous variables were expressed as the mean \pm standard and categorical variables were expressed as the absolute value. $\chi^{2}$ test was performed to evaluate the difference of the categorical variables between the groups. Analysis of variance (ANOVA) for age and education years was performed to assess the differences of groups. Analysis of covariance (ANCOVA) for other continuous variables was performed with age and years of education as

TABLE 1 | Polymerase chain reaction (PCR) primers used for single nucleotide polymorphism (SNP) analysis of FGF19, FGF21, and FGF23 genes.

\begin{tabular}{|c|c|c|}
\hline Polymorphism & Primer & Sequence $\left(5^{\prime}-3^{\prime}\right)$ \\
\hline \multirow[t]{3}{*}{ rs948992 } & R-primer & ACGTTGGATGTAACTTGCTGTCCCGGTGTC \\
\hline & F-primer & ACGTTGGATGAATCCATGGGGAGGCATGTG \\
\hline & $\begin{array}{l}\text { Single base } \\
\text { extension }\end{array}$ & CAGAGGGCTGGTGGGCTGGG \\
\hline \multirow[t]{3}{*}{ rs11665841 } & R-primer & ACGTTGGATGAGAGCGAGACTCCGTCTCAA \\
\hline & F-primer & ACGTTGGATGTACACCTCCCCTCACGTGG \\
\hline & $\begin{array}{l}\text { Single base } \\
\text { extension }\end{array}$ & AAAAAGTGAGGCCCA \\
\hline \multirow[t]{3}{*}{ rs11665896 } & R-primer & ACGTTGGATGCAGCTGTITGTCTCCCTTG \\
\hline & F-primer & ACGTTGGATGGAAAAAAGTGAGGCCCAGTG \\
\hline & $\begin{array}{l}\text { Single base } \\
\text { extension }\end{array}$ & CCCATCCCCTCACGTGGTCC \\
\hline \multirow[t]{3}{*}{ rs11063118 } & R-primer & ACGTTGGATGGCTCACGTTAATAGCTGGG \\
\hline & F-primer & ACGTTGGATGAATGGGCAGTGCAGACTAGG \\
\hline & $\begin{array}{l}\text { Single base } \\
\text { extension }\end{array}$ & TGGGGTTTGAACTCAGGCA \\
\hline \multirow[t]{3}{*}{ rs7955866 } & R-primer & ACGTTGGATGTCGAGTGAACACGCACGCTG \\
\hline & F-primer & ACGTTGGATGAGCGACCCTAGATGAACTTG \\
\hline & $\begin{array}{l}\text { Single base } \\
\text { extension }\end{array}$ & GGGCACACGCACGCTGGGGGAA \\
\hline
\end{tabular}


covariates using SPSS 20.0 (Statistical Package for Social Studies, Version 20.0, SPSS Inc., Chicago, IL, United States). HardyWeinberg equilibrium (HWE) test, linkage disequilibrium (LD) and the frequencies of the distribution of genotypes and alleles in both $\mathrm{AD}$-group and HC-group were analyzed using SHEsis and SHEsis-Plus platform ${ }^{2}$ (Shi and $\mathrm{He}, 2005$ ). Generalized multifactor dimensionality reduction (GMDR), a genetic modelfree alternative to logistic regression, is used to detect the interaction of gene and environment, which was performed to calculate the interaction of five loci (Lou et al., 2007). All tests were two-tailed, the $p$-value less than 0.05 was considered statistically significant.

\section{RESULTS}

\section{The General Characteristics of the Study Population}

In the present study as shown in Table 2, all the participants ranged from 20 to 67 years old $(40.63 \pm 11.68$ years) with the education years from 5 to 18 years $(10.78 \pm 3.48$ years). The age of subjects in the $\mathrm{AD}$-group was $44.08 \pm 11.96$ years and significantly higher than that of the HC-group $(p<0.001)$, but the education years of subjects of the former were $9.88 \pm 3.68$ years and significantly lower than that of the latter $(p<0.001)$. In the AD-group, the proportion of patients with never married was $9.3 \%$ and was significantly lower compared with the HC-group $(p<0.001)$. The rate of patients with divorce/widowed history was significantly higher than that of the HC-group after multiple comparisons $(p<0.001)$. The MAST (Chinese version) 19 was performed to evaluate the severity of $\mathrm{AD}$ and it is a 22-item self-scoring test.

\section{The Difference in Aggression Between the Two Groups}

Because the age and years of education were different between the two groups, ANCOVA was used to calculate the difference of aggression with the year of education as covariables, respectively. The Aggression Scale total score was $34.83 \pm 17.63$ in the ADgroup and higher than that of the HC-group $(21.71 \pm 15.04$; $p<0.001)$. Physical aggression of the AD-group was higher compared with the HC-group ( $37.13 \pm 21.01$ vs. $26.15 \pm 18.81$; $p<0.001)$. Verbal aggression also significantly increased in the AD-group (41.41 \pm 23.40 vs. $22.68 \pm 18.94 ; p<0.001)$. The level of anger in the $\mathrm{AD}$-group was $41.41 \pm 23.40$ and significantly higher than that of the HC-group $(p<0.001)$. The subjects in the $\mathrm{AD}$-group have stronger hostility than the HC-group $(30.579 \pm 19.18$ vs. $18.12 \pm 15.90 ; p<0.001)$. The levels of selfaggression also elevated in subjects with $\mathrm{AD}$ than that of the HC-group (33.10 \pm 20.05 vs. $15.01 \pm 16.72 ; p<0.001$; Table 3).

\section{The Association Between Aggression and MAST Scores}

The association between MAST scores and aggression related to $\mathrm{AD}$ were investigated with age and years of education

${ }^{2}$ http://analysis.bio-x.cn/myAnalysis.php
TABLE 2 | Clinical characteristics of all participants.

\begin{tabular}{lccc}
\hline Characteristics & AD $(\boldsymbol{n}=\mathbf{4 8 2})$ & HC $(\boldsymbol{n}=\mathbf{4 7 4})$ & $\boldsymbol{p}$ \\
\hline Age & $44.08 \pm 11.96$ & $37.07 \pm 10.24$ & $<0.001$ \\
Years of education & $9.88 \pm 3.68$ & $11.70 \pm 2.99$ & $<0.001$ \\
Marital status $\boldsymbol{n},(\%)$ & & & \\
Never married & $45(9.3 \%)$ & $105(22.2 \%)$ & $<0.001$ \\
Married & $362(75.1 \%)$ & $352(74.3 \%)$ & 0.765 \\
Divorced/widowed & $75(15.6 \%)$ & $17(3.6 \%)$ & $<0.001$ \\
Living conditions & & & \\
Live alone & $65(13.5 \%)$ & $87(18.4 \%)$ & 0.040 \\
Living ingroup quarters & $55(11.4 \%)$ & $58(12.2 \%)$ & 0.693 \\
Livingwith family & $362(75.1 \%)$ & $329(69.4 \%)$ & 0.049
\end{tabular}

$A D$, alcohol dependences; $H C$, healthy controls.

Analysis of variance was performed to analyze the difference of age and years of education between the groups. $x^{2}$ test was performed to evaluate the difference of the categorical variables between the groups.

TABLE 3 | The difference in aggression related to AD compared with the HC-group.

\begin{tabular}{lccc}
\hline $\begin{array}{l}\text { Aggression and } \\
\text { MAST scores }\end{array}$ & AD-group $(\boldsymbol{n}=\mathbf{4 8 2})$ & HC-group $(\boldsymbol{n}=\mathbf{4 7 4})$ & $\boldsymbol{p}$ \\
\hline $\begin{array}{l}\text { Aggression Scale } \\
\text { total score }\end{array}$ & $34.83 \pm 17.63$ & $21.71 \pm 15.04$ & $<0.001$ \\
Physical aggression & $37.13 \pm 21.01$ & $26.15 \pm 18.81$ & $<0.001$ \\
Verbal aggression & $37.72 \pm 19.87$ & $26.29 \pm 18.15$ & $<0.001$ \\
Anger & $41.41 \pm 23.40$ & $22.68 \pm 18.94$ & $<0.001$ \\
Hostility & $30.579 \pm 19.18$ & $18.12 \pm 15.90$ & $<0.001$ \\
Self-aggression & $33.10 \pm 20.05$ & $15.01 \pm 16.72$ & $<0.001$ \\
MAST scores & $10.09 \pm 5.07$ & $/$ & \\
\hline
\end{tabular}

$A D$, alcohol dependences; HC, healthy controls.

Analysis of covariance was performed to analyze the difference between the two groups with years of education as covariates.

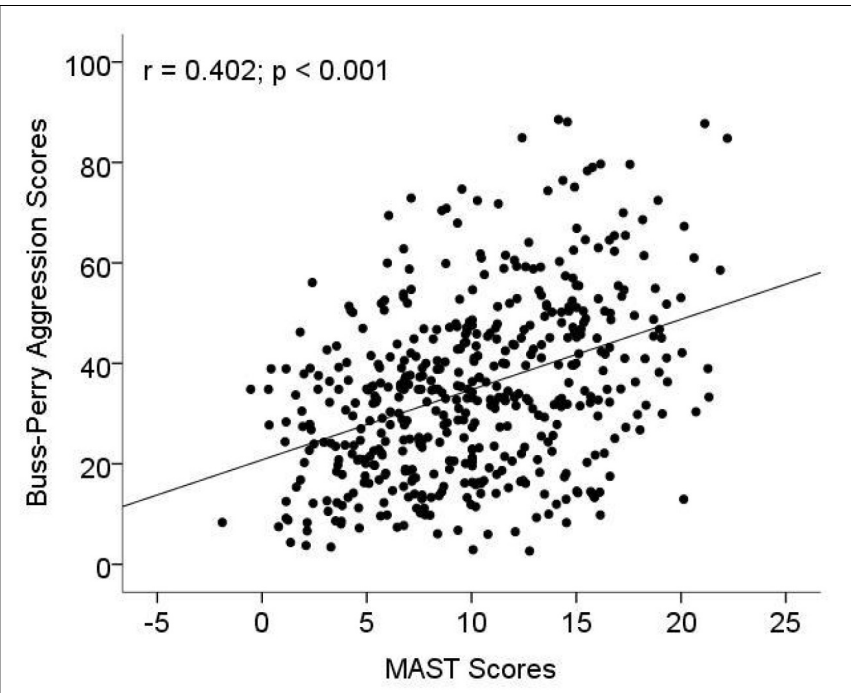

FIGURE 1 | The association between aggression and Michigan alcoholism screening test (MAST) scores. MAST was used to measure the level of alcohol dependence (AD), and a Chinese version of the Buss-Perry Aggression Questionnaire was used to evaluate the aggressive behavior of subjects. 
as covariables. The result showed that MAST scores were significantly positively associated Buss-Perry aggression scores $(r=0.402, p<0.001$; Figure 1). In multiple linear regression model, increased MAST scores contributed to Buss-Perry aggression scores (OR: 1.44, 95\%CI: 1.1-1.75) after being adjusted for age, education years and marital status (Table 4).

\section{Genetic Polymorphisms Analysis}

Genotype distributions of rs948992, rs11665841, rs11665896, rs7955866, and rs11063118 loci were consistent with HardyWeinberg proportions (AUD: $\chi^{2}=0.043, p=0.98 ; \chi^{2}=1.81$, $p=0.40 ; \chi^{2}=1.95, p=0.38 ; \chi^{2}=1.47, p=0.48 ; \chi^{2}=7.40$, $p=0.024$; HC: $\chi^{2}=0.13, p=0.94 ; \chi^{2}=3.12, p=0.21 ; \chi^{2}=2.33$, $p=0.31 ; \chi^{2}=0.46, p=0.79$; and $\chi^{2}=2.17, p=0.34$, respectively). As shown in Table 5, the distributions of genotypes and alleles of the five loci were not significantly different between the two groups, respectively (all $p>0.05$ ).

\section{Generalized Multifactor Dimensionality Reduction Analysis of Gene-Gene of FGF 19 and 21 Interaction for $A D$}

Generalized multifactor dimensionality reduction analysis was performed to evaluate the cross-validation consistency and the prediction error for each number of loci. The model of FGF21 rs11665896 - FGF19 rs948992 combination was significant $(p=0.010)$ with a training accuracy of $55.68 \%$ and testing accuracy of $53.97 \%$, and with a maximum cross-validation consistency (10/10) after permutation testing (Table 6). The two-locus genotype combinations related to different risk for each multilocus-genotype combination was analyzed and showed in Figure 2. The model of FGF21 rs11665896 (GG) - FGF19 rs948992 (TC) presented the high-risk genotype combination,

TABLE 4 | The multiple linear regression analysis of the association between MAST scores and Buss-Perry aggression scores.

\begin{tabular}{lccccc}
\hline \multirow{2}{*}{$\begin{array}{l}\text { Buss-Perry } \\
\text { aggression scores }\end{array}$} & \multicolumn{2}{c}{ Model 1 } & & \multicolumn{2}{c}{ Model 2 } \\
\cline { 2 - 3 } \cline { 5 - 6 } & $\boldsymbol{\beta}, \mathbf{9 5 \%} \mathbf{~ C l}$ & $\boldsymbol{p}$ & & $\boldsymbol{\beta}, \mathbf{9 5 \%} \mathbf{~ C l}$ & $\boldsymbol{p}$ \\
\hline MAST scores & $1.41(1.11-1.70)$ & $<0.001$ & $1.44(1.14-1.75)$ & $<0.001$
\end{tabular}

Model 1: unadjusted.

Model 2: adjusted for age, education years and marital status. and FGF21 rs11665896 (TT) - FGF19 rs948992 (TT) presented the low-risk genotype combinations (Figure 2).

\section{Generalized Multifactor Dimensionality Reduction Analysis of Gene-Gene Interaction for Aggression Associated With AD}

The model of FGF 19rs948992 - FGF21 rs11665896 - FGF23 rs11063118 combination was significant $(p=0.0017)$ with a training accuracy of $56.85 \%$ and testing accuracy of $50.32 \%$, and with a close to maximum cross-validation consistency (9/10) after permutation testing (Table 7). The two-locus genotype combinations related to a different risk for each multilocus-genotype combination is shown in Figure 3. In the model of FGF19 rs948992 - FGF21 rs11665896 - FGF23 rs11063118, (TC) - (TG) - (TT) presented the high-risk genotype combination, (CC) - (TT) - (CC) and (TT) - (TT) - (CC) presented the low-risk genotype combinations (Figure 3).

\section{DISCUSSION}

In the present study, we attempted to evaluate the association between AD-related aggression and genetic variants of the FGF19 subfamily members including FGF19, FGF21, and FGF23 genes in a Chinese population. No significant differences were found of frequencies of allelic distribution of 5 SNPs in three loci of FGFs between $\mathrm{AD}$ and $\mathrm{HC}$. We found that the aggression level of the $\mathrm{AD}$ subjects was higher than that of the $\mathrm{HC}$ group. Our results had also shown that the interaction of FGF21 rs11665896 GG × FGF19 rs948992 TC presented the high-risk genotype combination associated with $\mathrm{AD}$, and FGF21 rs11665896 TT $\times$ FGF19 rs948992 TT presented the low-risk genotype combinations of AD. In addition, FGF19 rs948992 TC $\times$ FGF21 rs11665896 TG $\times$ FGF23 rs11063118 TT presented the high-risk genotype combination of aggression associated with $\mathrm{AD}$.

The behavioral impairments related to alcohol have been reported in numerous studies about impulsivity, aggression, depression, suicidal behavior, and other mental disorders (Tobore, 2019). Alcohol-related aggression was a common violent behavior in individuals with $\mathrm{AD}$, it was considered a brain disfunction with cognitive disruption (Heinz et al., 2011). It has been suggested that alcohol could disrupt the crucial contents of

TABLE 5 | The frequencies of genotypic and allelic distributions of five loci.

\begin{tabular}{|c|c|c|c|c|c|c|c|c|}
\hline \multicolumn{2}{|r|}{ SNP } & \multirow[t]{2}{*}{ Major/minor allele } & \multicolumn{2}{|c|}{ Major allele frequency } & \multirow[t]{2}{*}{$p$} & \multicolumn{2}{|c|}{ Major allele frequency } & \multirow[t]{2}{*}{$p$} \\
\hline & & & $\mathrm{HC}$ & $A D$ & & HC (AA/Aa/aa) & AD (AA/Aa/aa) & \\
\hline FGF19 & rs948992 & $\mathrm{C} / \mathrm{T}$ & 0.51 & 0.54 & 0.27 & $121 / 225 / 112$ & $121 / 213 / 90$ & 0.49 \\
\hline \multirow[t]{2}{*}{ FGF21 } & rs11665841 & $\mathrm{C} / \mathrm{T}$ & 0.68 & 0.69 & 0.76 & $230 / 187 / 55$ & $219 / 177 / 48$ & 0.93 \\
\hline & rs11665896 & $\mathrm{G} / \mathrm{T}$ & 0.68 & 0.69 & 0.84 & 230/190/54 & 219/178/49 & 0.92 \\
\hline \multirow[t]{2}{*}{ FGF23 } & rs7955866 & $\mathrm{G} / \mathrm{A}$ & 0.84 & 0.85 & 0.52 & $337 / 123 / 14$ & $327 / 106 / 13$ & 0.76 \\
\hline & rs11063118 & $\mathrm{T} / \mathrm{C}$ & 0.80 & 0.81 & 0.68 & $308 / 141 / 24$ & 298/119/25 & 0.61 \\
\hline
\end{tabular}

$A A=$ major allele homozygous; $A a$ = heterozygous; $a a$ = minor allele. 
TABLE 6 | The best model for predicting the occurrence of AD.

\begin{tabular}{|c|c|c|c|c|c|c|}
\hline Best model $^{a}$ & Training accuracy (\%) & Testing accuracy (\%) & CVC & $x^{2}$ & $p$ & $95 \% \mathrm{Cl}$ \\
\hline 1 & 52.71 & 37.80 & $6 / 10$ & 1.07 & 0.302 & $1.24(0.82,1.88)$ \\
\hline 1,2 & 55.68 & 53.97 & $10 / 10$ & 6.51 & 0.010 & $1.74(1.13,2.66)$ \\
\hline $1,2,3$ & 57.26 & 51.21 & $5 / 10$ & 0.0064 & 0.936 & $1.05(0.29,3.71)$ \\
\hline $1,2,3,4$ & 58.66 & 51.82 & $8 / 10$ & 0.715 & 0.398 & $1.72(0.48,6.08)$ \\
\hline $1,2,3,4,5$ & 59.37 & 50.71 & $10 / 10$ & 1.004 & 0.316 & $1.97(0.52,7.50)$ \\
\hline
\end{tabular}

a Number 1-5 represented FGF19 rs948992, FGF21 rs11665896, FGF23 rs11063118, FGF23 rs7955866, and FGF21 rs11665841, respectively.

social information and further engendered aggressive behavior under mis-interpretation (Beck and Heinz, 2013; Parrott and Eckhardt, 2018). But this association showed a controversial result with the development of alcohol exposure. Some studies suggested that increasing alcohol consumption was associated with violent behaviors including aggression (Stappenbeck and Fromme, 2010; Sacco et al., 2015). In an animal model, alcoholrelated aggression increased with elevated doses of alcohol, but the dose-dependent association might be disrupted by higher doses (Weerts et al., 1993). Other studies reported that alcoholrelated aggression did not happen much in individuals with $\mathrm{AD}$ (Murphy et al., 2005; Beck and Heinz, 2013). Thus, acute and excessive alcohol consumption seemed to more likely engender aggressive behavior (Fals-Stewart, 2003). In our study, higher MAST scores presented a higher risk of aggression in individuals with AD.

The studies about the genetic link between the FGF21 gene and alcohol intake increased gradually. It has been demonstrated that rs838133 and rs838145 were associated with higher carbohydrate intake, which also may affect alcohol intake (von Holstein-Rathlou and Gillum, 2019). The two SNPs in this present study, including rs11665896 and rs11665841, only rs11665896 was confirmed to influence carbohydrate metabolic (Ruiz-Padilla et al., 2019). Another study attempted to assess the association between rs11665841 and carbohydrate metabolism, but no significant association was found (Zhang et al., 2012). Although FGF19 mRNA overexpression was associated with alcohol-related decreases (Zhang et al., 2013), whether the SNPs of FGF19 including rs948992 were related to alcohol intake remains not clear. In this study, we found the interaction of FGF19 rs948992 TC $\times$ FGF21 rs11665896 GG presented the high-risk genotype combination associated with $\mathrm{AD}$.

MicroRNAs constitute a growing class of non-coding RNAs that suppress target gene protein translation by combining with 3' UTR (Bartel, 2004). Rs948992 is located on 3' UTR of FGF19 gene, and rs1166584 and rs11665896 are both located about 500 bp downstream at $3^{\prime}$ end of the FGF21 gene, based on dbSNP database. The T allele of rs11665896 carriers consumed higher amounts of carbohydrates compared to carrying the GG or GT genotypes (Ruiz-Padilla et al., 2019), and alcohol in circulation was delayed in the G allele carriers compared to the $\mathrm{T}$ carriers, which means that the metabolic capability of GG genotype for alcohol may be weaker than the TT genotype. In addition, the two SNPs are located at the $3^{\prime}$ UTR region, in which target sites for miRNAs are located and their genetic variants were associated with genotype alteration (Zhang et al.,
2012). Speculatively, the change of allele exchange resulting from these loci could affect miRNA binding, perhaps reducing FGF19 and FGF21 transcription, as it has been shown for other genes (Sethupathy and Collins, 2008; Moszynska et al., 2017). In the present study, the interaction combination of FGF19 rs948992 TC $\times$ FGF21 rs11665896 TG $\times$ FGF23 rs11063118 TT showed a significant correlation with aggression associated with AD.

Some limitations of the present study should be noted. Firstly, the age and the years of education were not well-matched between the $\mathrm{HC}$ and $\mathrm{AD}$ subjects. The age and education years may have effects on aggression, although the conclusions about the effects of age and education years on aggression are inconsistent in previous studies. A recent study suggested that physical aggression declined with age in boys instead of girls, but indirect aggression increased with age in girls, such as anger and hostility (Tsorbatzoudis et al., 2013). Another study suggested that age had bi-directional moderating effects

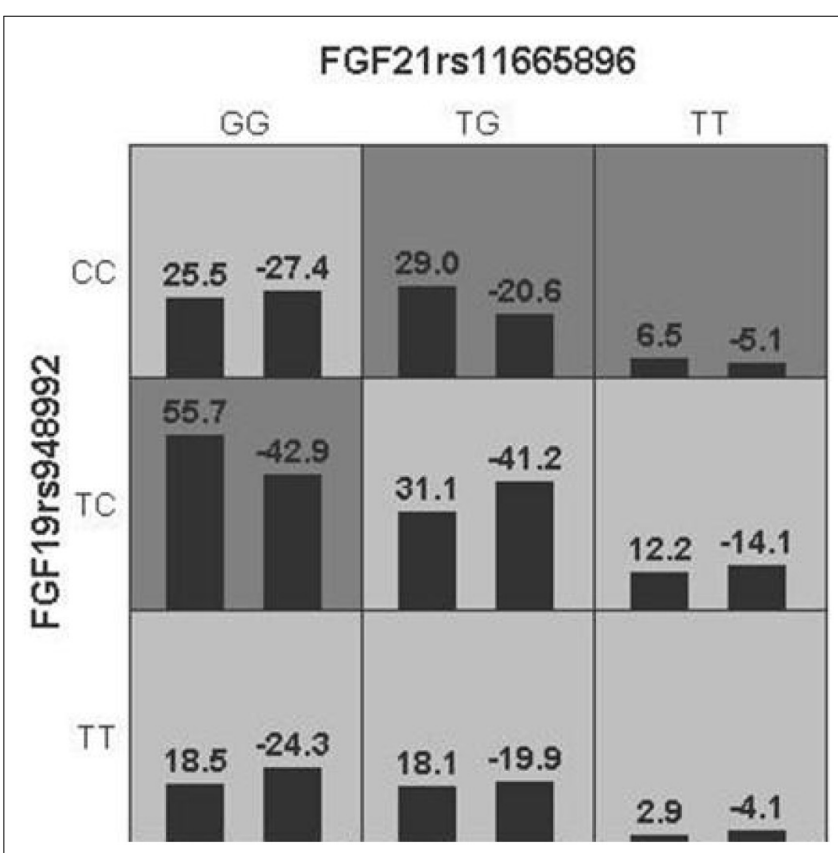

FIGURE 2 | The best model based on generalized multifactor dimensionality reduction (GMDR) analyses showed the interaction effect of FGF19 rs948992 TC $\times$ FGF21 rs11665896 GG on AD. The shaded dark gray cell presented a high-risk combination and shaded light gray presented a low-risk combination. 
TABLE 7 | The best model for predicting the aggression in AD.

\begin{tabular}{|c|c|c|c|c|c|c|}
\hline Best model $^{a}$ & Training accuracy (\%) & Testing accuracy (\%) & CVC & $x^{2}$ & $p$ & $95 \% \mathrm{Cl}$ \\
\hline 1 & 53.32 & 50.78 & $9 / 10$ & 0.23 & 0.629 & $0.94(0.76,1.18)$ \\
\hline 1,2 & 54.09 & 50.32 & $8 / 10$ & 1.39 & 0.237 & $0.87(0.70,1.09)$ \\
\hline $1,2,3$ & 56.85 & 52.66 & $9 / 10$ & 9.89 & 0.0017 & $1.44(1.15,1.80)$ \\
\hline $1,2,3,4$ & 58.19 & 51.43 & $6 / 10$ & 0.568 & 0.451 & $1.08(0.88,1.33)$ \\
\hline $1,2,3,4,5$ & 59.33 & 53.88 & $10 / 10$ & 0.213 & 0.644 & $0.95(0.75,1.19)$ \\
\hline
\end{tabular}

a Number 1-5 represented FGF19 rs948992, FGF21 rs11665896, FGF23 rs11063118, FGF23 rs7955866, and FGF21 rs11665841, respectively.

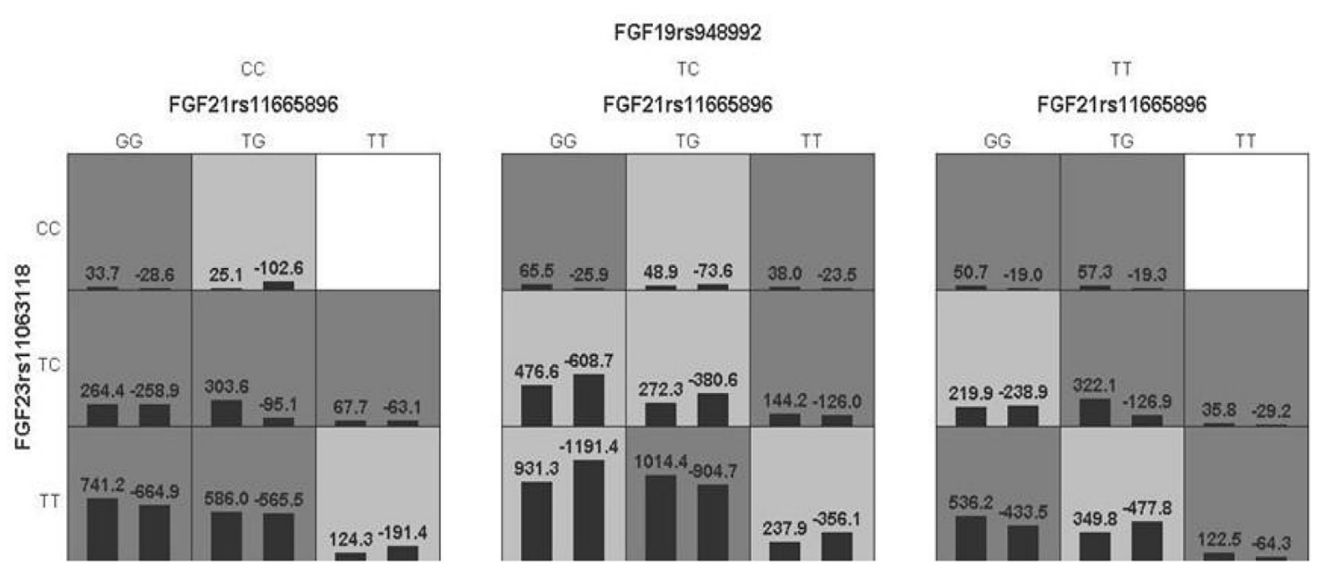

FIGURE 3 | The best model based on GMDR analyses showed the interaction effect of FGF19 rs948992 TC $\times$ FGF21 rs11665896 TG $\times$ FGF23 rs11063118 TT on AD related aggression. The shaded dark gray cell presented a high-risk combination and shaded light gray presented a low-risk combination.

on aggression based on the levels of reactive aggression (Smeets et al., 2017). Generally for male drinkers, daily alcohol intake increases with age but declines in those with more education ( $\mathrm{Li}$ et al., 2014). Perpetrators of peer aggression were reported to be associated with non-completion of secondary school (Moore et al., 2015) and aggression negatively predicted higher education (Rabinowitz et al., 2020). Although the statistical analysis of ANCOVA was performed with age and education years as covariates to weaken the influence of age and education year differences on aggression between the $\mathrm{HC}$ and AD groups, age and education year differences might still possibly cause the observed difference in the aggression of $\mathrm{HC}$ and $\mathrm{AD}$ groups in the present study. Secondly, more variations of these three genes, including tags and functional variations should be genotyped to obtain more information. Finally, the information of SNPs on FGF 23 in $\mathrm{AD}$ and aggression is rare, and needs to be further investigated.

\section{CONCLUSION}

The aggression increases significantly associated with the level of $\mathrm{AD}$ in the $\mathrm{AD}$ subjects. The interaction of FGF19 rs948992 TC $\times$ FGF21 rs11665896 GG presented the highrisk genotype combination predicting the high level of AD. In addition, the interaction of FGF19 rs948992 TC $\times$ FGF21 rs11665896 TG $\times$ FGF23 rs11063118 TT presented the high-risk genotype combination predicting the high level of aggression in $\mathrm{AD}$ patients.

\section{DATA AVAILABILITY STATEMENT}

The raw data supporting the conclusions of this article will be made available by the authors, without undue reservation.

\section{AUTHOR CONTRIBUTIONS}

$\mathrm{JH}$ and HX conceived and designed the research. JX, FeW, FaW, FY, MLi, MLo, LW, and JH performed the experiments and wrote the manuscript together. HL and YF supplied the important and thoughtful advice and performed the experiments. LC, YL, and WL performed the statistical analysis and supplied much technology and fund assistant. FeW performed the experiments and wrote the manuscript, and made an important contribution to the work. All authors discussed the drafting of the manuscript. HX edited the last version of the manuscript.

\section{FUNDING}

This work was supported by the Basic and public research project of Zhejiang province (LGF18H020001), the Open Project Program of Key Laboratory of Drug Prevention and Control Technology of Zhejiang Province (2020012), the Natural Science Foundation of Xinjiang Uyghur Autonomous Region (2018D01C228), the Health Technology Program in Zhejiang Province (2017KY720), the Fujian Provincial Health Commission (2017-CXB-17), and the National Nature Science Foundation of China (81671266). 


\section{REFERENCES}

Abrahao, K. P., Salinas, A. G., and Lovinger, D. M. (2017). Alcohol and the brain: neuronal molecular targets, synapses, and circuits. Neuron 96, 1223-1238. doi: 10.1016/j.neuron.2017.10.032

Bartel, D. P. (2004). MicroRNAs: genomics, biogenesis, mechanism, and function. Cell 116, 281-297. doi: 10.1016/s0092-8674(04)00045-5

Beck, A., and Heinz, A. (2013). Alcohol-related aggression-social and neurobiological factors. Dtsch. Arztebl. Int. 110, 711-715. doi: 10.3238/ arztebl.2013.0711

Brandl, K., Hartmann, P., Jih, L. J., Pizzo, D. P., Argemi, J., Ventura-Cots, M., et al. (2018). Dysregulation of serum bile acids and FGF19 in alcoholic hepatitis. J. Hepatol. 69, 396-405. doi: 10.1016/j.jhep.2018.03.031

Brodie, M. J., Besag, F., Ettinger, A. B., Mula, M., Gobbi, G., Comai, S., et al. (2016). Epilepsy, antiepileptic drugs, and aggression: an evidence-based review. Pharmacol. Rev. 68, 563-602. doi: 10.1124/pr.115.012021

Buss, A. H., and Perry, M. (1992). The aggression questionnaire. J. Pers. Soc. Psychol. 63, 452-459. doi: 10.1037//0022-3514.63.3.452

Chen, K., and Rajewsky, N. (2006). Natural selection on human microRNA binding sites inferred from SNP data. Nat. Genet. 38, 1452-1456. doi: 10.1038/ng1910

Chester, D. S., Bucholz, K. K., Chan, G., Kamarajan, C., Pandey, A. K., Wetherill, L., et al. (2020). Alcohol-related, drug-related, and non-substance-related aggression: 3 facets of a single construct or 3 distinct constructs? Alcohol. Clin. Exp. Res. 44, 1852-1861. doi: 10.1111/acer.14412

Chiavaroli, A., Recinella, L., Ferrante, C., Martinotti, S., Vacca, M., Brunetti, L., et al. (2017). Effects of central fibroblast growth factor 21 and irisin in anxiety-like behavior. J. Biol. Regul. Homeost. Agents 31, 797-802.

Desai, B. N., Singhal, G., Watanabe, M., Stevanovic, D., Lundasen, T., Fisher, F. M., et al. (2017). Fibroblast growth factor 21 (FGF21) is robustly induced by ethanol and has a protective role in ethanol associated liver injury. Mol. Metab. 6, 1395-1406. doi: 10.1016/j.molmet.2017.08.004

Dick, D. M., and Agrawal, A. (2008). The genetics of alcohol and other drug dependence. Alcohol Res. Health 31, 111-118.

Dolegowska, K., Marchelek-Mysliwiec, M., Nowosiad-Magda, M., Slawinski, M., and Dolegowska, B. (2019). FGF19 subfamily members: FGF19 and FGF21. J. Physiol. Biochem. 75, 229-240. doi: 10.1007/s13105-019-00675-7

Epperlein, S., Gebhardt, C., Rohde, K., Chakaroun, R., Patt, M., Schamarek, I., et al. (2021). The effect of FGF21 and its genetic variants on food and drug cravings, adipokines and metabolic traits. Biomedicines 9:345. doi: 10.3390/ biomedicines 9040345

Erickson, E. K., Blednov, Y. A., Harris, R. A., and Mayfield, R. D. (2019). Glial gene networks associated with alcohol dependence. Sci. Rep. 9:10949. doi: 10.1038/ s41598-019-47454-4

Fals-Stewart, W. (2003). The occurrence of partner physical aggression on days of alcohol consumption: a longitudinal diary study. J. Consult. Clin. Psychol. 71, 41-52. doi: 10.1037//0022-006x.71.1.41

Frayling, T. M., Beaumont, R. N., Jones, S. E., Yaghootkar, H., Tuke, M. A., Ruth, K. S., et al. (2018). A common allele in FGF21 associated with sugar intake is associated with body shape, lower total body-fat percentage, and higher blood pressure. Cell Rep. 23, 327-336. doi: 10.1016/j.celrep.2018.03.070

Gan, G., Sterzer, P., Marxen, M., Zimmermann, U. S., and Smolka, M. N. (2015). Neural and behavioral correlates of alcohol-induced aggression under provocation. Neuropsychopharmacology 40, 2886-2896. doi: 10.1038/npp.2015. 141

Gibson, E. L. (2018). Tryptophan supplementation and serotonin function: genetic variations in behavioural effects. Proc. Nutr. Soc. 77, 174-188. doi: 10.1017/ S0029665117004451

Gonzalez-Reimers, E., Romero-Acevedo, L., Espelosin-Ortega, E., MartinGonzalez, M. C., Quintero-Platt, G., Abreu-Gonzalez, P., et al. (2018). Soluble klotho and brain atrophy in alcoholism. Alcohol Alcohol. 53, 503-510. doi: 10.1093/alcalc/agy037

Grant, B. F., Goldstein, R. B., Saha, T. D., Chou, S. P., Jung, J., Zhang, H., et al. (2015). Epidemiology of DSM-5 alcohol use disorder: results from the national epidemiologic survey on alcohol and related conditions III. JAMA Psychiatry 72, 757-766. doi: 10.1001/jamapsychiatry.2015.0584

Han, W., Tellez, L. A., Niu, J., Medina, S., Ferreira, T. L., Zhang, X., et al. (2016). Striatal dopamine links gastrointestinal rerouting to altered sweet appetite. Cell Metab. 23, 103-112. doi: 10.1016/j.cmet.2015.10.009
Heianza, Y., Ma, W., Huang, T., Wang, T., Zheng, Y., Smith, S. R., et al. (2016). Macronutrient intake-associated FGF21 genotype modifies effects of weightloss diets on 2-year changes of central adiposity and body composition: The POUNDS lost trial. Diabetes Care 39, 1909-1914. doi: 10.2337/dc161111

Heinz, A. J., Beck, A., Meyer-Lindenberg, A., Sterzer, P., and Heinz, A. (2011). Cognitive and neurobiological mechanisms of alcohol-related aggression. Nat. Rev. Neurosci. 12, 400-413. doi: 10.1038/nrn3042

Kharitonenkov, A., and DiMarchi, R. (2017). Fibroblast growth factor 21 night watch: advances and uncertainties in the field. J. Intern. Med. 281, 233-246. doi: $10.1111 /$ joim. 12580

Kiive, E., Laas, K., Vaht, M., Veidebaum, T., and Harro, J. (2017). Stressful life events increase aggression and alcohol use in young carriers of the GABRA2 rs279826/rs279858 A-allele. Eur. Neuropsychopharmacol. 27, 816-827. doi: 10. 1016/j.euroneuro.2017.02.003

Landi, D., Gemignani, F., Barale, R., and Landi, S. (2008). A catalog of polymorphisms falling in microRNA-binding regions of cancer genes. DNA Cell Biol. 27, 35-43. doi: 10.1089/dna.2007.0650

Li, Y., Zhang, M., Jiang, Y., Deng, Q., Zhao, Y., Huang, Z., et al. (2014). [Drinking behaviors and patterns among floating population aged 18-59 years old in China, 2012]. Zhonghua Liu Xing Bing Xue Za Zhi 35, 1186-1191.

Lou, X. Y., Chen, G. B., Yan, L., Ma, J. Z., Zhu, J., Elston, R. C., et al. (2007). A generalized combinatorial approach for detecting gene-by-gene and gene-byenvironment interactions with application to nicotine dependence. Am. J. Hum. Genet. 80, 1125-1137. doi: 10.1086/518312

Malamut, S. T., van den Berg, Y. H. M., Lansu, T. A. M., and Cillessen, A. H. N. (2021). Bidirectional associations between popularity, popularity goal, and aggression, alcohol use and prosocial behaviors in adolescence: a 3-year prospective longitudinal study. J. Youth Adolesc. 50, 298-313. doi: 10.1007/ s10964-020-01308-9

Miller, S. A., Dykes, D. D., and Polesky, H. F. (1988). A simple salting out procedure for extracting DNA from human nucleated cells. Nucleic Acids Res. 16:1215. doi: 10.1093/nar/16.3.1215

Moore, S. E., Scott, J. G., Thomas, H. J., Sly, P. D., Whitehouse, A. J., Zubrick, S. R., et al. (2015). Impact of adolescent peer aggression on later educational and employment outcomes in an Australian cohort. J. Adolesc. 43, 39-49. doi: 10.1016/j.adolescence.2015.05.007

Moszynska, A., Gebert, M., Collawn, J. F., and Bartoszewski, R. (2017). SNPs in microRNA target sites and their potential role in human disease. Open Biol. 7:170019. doi: 10.1098/rsob.170019

Murphy, C. M., Winters, J., O'Farrell, T. J., Fals-Stewart, W., and Murphy, M. (2005). Alcohol consumption and intimate partner violence by alcoholic men: comparing violent and nonviolent conflicts. Psychol. Addict. Behav. 19, 35-42. doi: 10.1037/0893-164x.19.1.35

Nedic Erjavec, G., Nenadic Sviglin, K., Nikolac Perkovic, M., Muck-Seler, D., Jovanovic, T., and Pivac, N. (2014). Association of gene polymorphisms encoding dopaminergic system components and platelet MAO-B activity with alcohol dependence and alcohol dependence-related phenotypes. Prog. Neuropsychopharmacol. Biol. Psychiatry 54, 321-327. doi: 10.1016/j.pnpbp. 2014.07.002

Newman, E. L., Terunuma, M., Wang, T. L., Hewage, N., Bicakci, M. B., Moss, S. J., et al. (2018). A role for prefrontal cortical NMDA receptors in murine alcohol-heightened aggression. Neuropsychopharmacology 43, 1224-1234. doi: 10.1038/npp.2017.253

Nguyen, M., Boutignon, H., Mallet, E., Linglart, A., Guillozo, H., Jehan, F., et al. (2010). Infantile hypercalcemia and hypercalciuria: new insights into a vitamin D-dependent mechanism and response to ketoconazole treatment. J. Pediatr. 157, 296-302. doi: 10.1016/j.jpeds.2010.02.025

Park, C. I., Kim, H. W., Hwang, S. S., Kang, J. I., and Kim, S. J. (2019). Influence of dopamine-related genes on craving, impulsivity, and aggressiveness in Korean males with alcohol use disorder. Eur. Arch. Psychiatry Clin. Neurosci. 271, 865-872. doi: 10.1007/s00406-019-01072-3

Parrott, D. J., and Eckhardt, C. I. (2018). Effects of alcohol on human aggression. Curr. Opin. Psychol. 19, 1-5. doi: 10.1016/j.copsyc.2017.03.023

Plemenitas, A., Kores Plesnicar, B., Kastelic, M., Porcelli, S., Serretti, A., and Dolzan, V. (2015). Genetic variability in tryptophan hydroxylase 2 gene in alcohol dependence and alcohol-related psychopathological symptoms. Neurosci. Lett. 604, 86-90. doi: 10.1016/j.neulet.2015.07.037 
Quintero-Platt, G., Gonzalez-Reimers, E., Rodriguez-Gaspar, M., MartinGonzalez, C., Perez-Hernandez, O., Romero-Acevedo, L., et al. (2017). Alpha klotho and fibroblast growth factor-23 among alcoholics. Alcohol Alcohol. 52, 542-549. doi: 10.1093/alcalc/agx041

Rabinowitz, J. A., Kuo, S. I., Domingue, B., Smart, M., Felder, W., Benke, K., et al. (2020). Pathways between a polygenic score for educational attainment and higher educational attainment in an African American sample. Behav. Genet. 50, 14-25. doi: 10.1007/s10519-019-09982-7

Recinella, L., Leone, S., Ferrante, C., Chiavaroli, A., Di Nisio, C., Martinotti, S., et al. (2017). Effects of central fibroblast growth factor 21 (FGF21) in energy balance. J. Biol. Regul. Homeost. Agents 31, 603-613.

Roozen, H. G., Wetering, B. J., and Franken, I. H. (2013). Does alcohol craving mediate the impulsivity-aggression relationship in recently detoxified alcoholdependent patients? Am. J. Drug Alcohol Abuse 39, 57-60. doi: 10.3109/ 00952990.2012 .677888

Rothe, H., Brandenburg, V., Haun, M., Kollerits, B., Kronenberg, F., Ketteler, M., et al. (2017). Ecto-5' -Nucleotidase CD73 (NT5E), vitamin D receptor and FGF23 gene polymorphisms may play a role in the development of calcific uremic arteriolopathy in dialysis patients - Data from the German Calciphylaxis registry. PLoS One 12:e172407. doi: 10.1371/journal.pone. 0172407

Ruiz-Padilla, A. J., Morales-Hernandez, G., Ruiz-Noa, Y., Alonso-Castro, A. J., Lazo-de-la-Vega-Monroy, M. L., Preciado-Puga, M. D. C., et al. (2019). Association of the $3^{\prime}$ UTR polymorphism (rs11665896) in the FGF21 gene with metabolic status and nutrient intake in children with obesity. J. Pediatr. Endocrinol. Metab. 32, 921-928. doi: 10.1515/jpem-2018-0546

Sacco, P., Bright, C. L., Jun, H. J., and Stapleton, L. M. (2015). Developmental relations between alcohol and aggressive behavior among adolescents: neighborhood and sociodemographic correlates. Int. J. Ment. Health Addict. 13, 603-617. doi: 10.1007/s11469-015-9546-1

Schuckit, M. A. (2009). Alcohol-use disorders. Lancet 373, 492-501. doi: 10.1016/ S0140-6736(09)60009-X

Schumann, G., Liu, C., O’Reilly, P., Gao, H., Song, P., Xu, B., et al. (2016). KLB is associated with alcohol drinking, and its gene product $\beta$-Klotho is necessary for FGF21 regulation of alcohol preference. Proc. Natl. Acad. Sci. U.S.A. 113, 14372-14377. doi: 10.1073/pnas.1611243113

Selzer, M. L. (1971). The Michigan alcoholism screening test: the quest for a new diagnostic instrument. Am. J. Psychiatry 127, 1653-1658. doi: 10.1176/ajp.127. 12.1653

Sethupathy, P., and Collins, F. S. (2008). MicroRNA target site polymorphisms and human disease. Trends Genet. 24, 489-497. doi: 10.1016/j.tig.2008.07.004

Shi, Y. Y., and He, L. (2005). SHEsis, a powerful software platform for analyses of linkage disequilibrium, haplotype construction, and genetic association at polymorphism loci. Cell Res. 15, 97-98. doi: 10.1038/sj.cr.7290272

Skinner, H. A. (1982). The drug abuse screening test. Addict. Behav. 7, 363-371. doi: 10.1016/0306-4603(82)90005-3

Smeets, K. C., Oostermeijer, S., Lappenschaar, M., Cohn, M., van der Meer, J. M., Popma, A., et al. (2017). Are proactive and reactive aggression meaningful distinctions in adolescents? A variable- and person-based approach. J. Abnorm. Child Psychol. 45, 1-14. doi: 10.1007/s10802-016-0149-5

Soberg, S., Andersen, E. S., Dalsgaard, N. B., Jarlhelt, I., Hansen, N. L., Hoffmann, N., et al. (2018). FGF21, a liver hormone that inhibits alcohol intake in mice, increases in human circulation after acute alcohol ingestion and sustained binge drinking at Oktoberfest. Mol. Metab. 11, 96-103. doi: 10.1016/j.molmet.2018. 03.010

Soberg, S., Sandholt, C. H., Jespersen, N. Z., Toft, U., Madsen, A. L., von HolsteinRathlou, S., et al. (2017). FGF21 is a sugar-induced hormone associated with sweet intake and preference in humans. Cell Metab. 25, 1045-1053.e6. doi: 10.1016/j.cmet.2017.04.009
Song, P., Zechner, C., Hernandez, G., Cánovas, J., Xie, Y., Sondhi, V., et al. (2018). The hormone FGF21 stimulates water drinking in response to ketogenic diet and alcohol. Cell Metab. 27, 1338-1347.e4. doi: 10.1016/j.cmet.2018.04.001

Stappenbeck, C. A., and Fromme, K. (2010). A longitudinal investigation of heavy drinking and physical dating violence in men and women. Addict.Behav. 35 , 479-485. doi: 10.1016/j.addbeh.2009.12.027

Tian, W., Wang, F., Cai, J. H., and Li, L. X. (2008). Polymorphic insertions in 5 Alu loci within the major histocompatibility complex class I region and their linkage disequilibria with HLA alleles in four distinct populations in mainland China. Tissue Antigens 72, 559-567. doi: 10.1111/j.1399-0039.2008.01152.x

Tobore, T. O. (2019). On the neurobiological role of oxidative stress in alcoholinduced impulsive, aggressive and suicidal behavior. Subst. Use Misuse 54, 2290-2303. doi: 10.1080/10826084.2019.1645179

Tsorbatzoudis, H., Travlos, A. K., and Rodafinos, A. (2013). Gender and age differences in self-reported aggression of high school students. J. Interpers. Violence 28, 1709-1725. doi: 10.1177/0886260512468323

von Holstein-Rathlou, S., and Gillum, M. P. (2019). Fibroblast growth factor 21: an endocrine inhibitor of sugar and alcohol appetite. J. Physiol. 597, 3539-3548. doi: $10.1113 /$ jp277117

Waltes, R., Chiocchetti, A. G., and Freitag, C. M. (2016). The neurobiological basis of human aggression: a review on genetic and epigenetic mechanisms. Am. J. Med. Genet. B Neuropsychiatr. Genet. 171, 650-675. doi: 10.1002/ajmg.b.32388

Weerts, E. M., Tornatzky, W., and Miczek, K. A. (1993). Prevention of the proaggressive effects of alcohol in rats and squirrel monkeys by benzodiazepine receptor antagonists. Psychopharmacology (Berl.) 111, 144-152. doi: 10.1007/ bf02245516

Witkiewitz, K., Litten, R. Z., and Leggio, L. (2019). Advances in the science and treatment of alcohol use disorder. Sci. Adv. 5:eaax4043. doi: 10.1126/sciadv. aax4043

Yang, L., Wang, F., Wang, M., Han, M., Hu, L., Zheng, M., et al. (2017). Association between oxytocin and receptor genetic polymorphisms and aggression in a northern Chinese Han population with alcohol dependence. Neurosci. Lett. 636, 140-144. doi: 10.1016/j.neulet.2016.10.066

Zhang, C., Ojiaku, P., and Cole, G. J. (2013). Forebrain and hindbrain development in zebrafish is sensitive to ethanol exposure involving agrin, Fgf, and sonic hedgehog function. Birth Defects Res. A Clin. Mol. Teratol. 97, 8-27. doi: 10. 1002/bdra.23099

Zhang, M., Zeng, L., Wang, Y. J., An, Z. M., and Ying, B. W. (2012). Associations of fibroblast growth factor 21 gene 3' untranslated region single-nucleotide polymorphisms with metabolic syndrome, obesity, and diabetes in a Han Chinese population. DNA Cell Biol. 31, 547-552. doi: 10.1089/dna.2011.1302

Conflict of Interest: The authors declare that the research was conducted in the absence of any commercial or financial relationships that could be construed as a potential conflict of interest.

Publisher's Note: All claims expressed in this article are solely those of the authors and do not necessarily represent those of their affiliated organizations, or those of the publisher, the editors and the reviewers. Any product that may be evaluated in this article, or claim that may be made by its manufacturer, is not guaranteed or endorsed by the publisher.

Copyright (C) $2021 \mathrm{Xu}, \mathrm{Wu}$, Wang, Yang, Liu, Lou, Wu, Li, Lin, Fan, Chen, Liu, Xu and He. This is an open-access article distributed under the terms of the Creative Commons Attribution License (CC BY). The use, distribution or reproduction in other forums is permitted, provided the original author(s) and the copyright owner(s) are credited and that the original publication in this journal is cited, in accordance with accepted academic practice. No use, distribution or reproduction is permitted which does not comply with these terms. 